\title{
Combination of the Reduction Reaction in the Cement Plant DeNox by the Extended Precalciner Module and Intelligent SNCR System Upgradation
}

\author{
Weiqiang LIU ${ }^{1}$ \\ Department of Cement Engineering, AVIC International Beijing Co., Ltd, Beijing \\ 100176, China
}

\begin{abstract}
Nox emission is required to be less than $50 \mathrm{Mg} / \mathrm{Nm}^{3}$ for cement industry according to the environmental policies in some provinces. As Nox can be chemically reduced to $\mathrm{N}_{2}$ by reduction reaction, this paper will introduce a new method by the combination of two reduction reaction to reduce the Nox emission in cement plant. One reduction reaction is reducing the Nox by $\mathrm{CO}$ which is produced in the extended gasifier calciner. Another reduction reaction is reducing the Nox by ammonia which is produced by spraying the ammonia water in the pre-calciner outlet where temperature is between $850^{\circ} \mathrm{C}$ and $950^{\circ} \mathrm{C}$ which is considered as the best reaction temperature range for this reduction reaction. Also, the intelligent SNCR system is introduced in the reduction reaction to control the reaction amount of the ammonia water. The intelligent SNCR system can forecast the working situation by studying the clinker calcining system process data. In this way, Both the Nox emission and the ammonia consumption can be substantially reduced.
\end{abstract}

Keywords. Nox emission, cement plant, intelligent SNCR system, environment protection

\section{Introduction}

With the stricter environment policy in China. A few provinces government have announce that the Nox emission should be lower than $50 \mathrm{mg} / \mathrm{Nm} 3$ for cement plants. This new policy pushes the Nox emission controlling innovation, Different with the SCR technology which is widely applied power generation plants, Because of the high dust density in cement plant, SCR technology will have the difficulties in handling the high dust. This paper will introduce a new method in reducing the Nox emission in cement plant.

The main purpose of a calciner in the cement production process is still the decomposition of calcite from the preheated raw meal. This is the most energy-intensive process during the production of clinker in a cement plant. The use of calciners results in a considerable reduction of the kiln's thermal load, enabling much higher clinker

${ }^{1}$ Corresponding Author, Weiqiang LIU, Department of Cement Engineering, AVIC International Beijing Co., Ltd, Beijing 100176, China; E-mail: 470190329@qq.com. 
capacities with the same kiln size [1]. Today the main drivers for further development are the necessity to reduce emissions such as NOx to meet emission limits.

\section{Calcination Process in Pyro System}

The calciner, installed between the preheater and the rotary kiln and directly supplied via the tertiary air duct with hot recuperation air from the clinker cooler, is responsible for almost completely calcining the hot meal before it is fed into the kiln. To perform the precalcination, 55 to 60 per cent of the total fuel is supplied to the calciner, which then can be expected to achieve a hot meal precalcination rate of 90-97 per cent. Depending on the raw material and fuel used, this corresponds to a temperature of $860-890^{\circ} \mathrm{C}$ at the calciner outlet. Higher precalcination rates result in a considerable rise in temperature in the calciner, which causes increasingly severe coating in the calciner, bottom cyclone and inlet chamber, leading to corresponding operational issues.

Combustion in the calciner takes place under totally different conditions from firing in the kiln. Due to mixing tertiary air with kiln exhaust gas, a lower oxygen concentration is present in most calciners. The preheated hot meal is supplied in the immediate vicinity of the fuel feed point.

The energy liberated during the oxidation of the fuel components is directly used for calcining the meal, which results in low overall combustion temperatures. In addition, the gaseous $\mathrm{CO}_{2}$ formed during the calcination reaction has a further retardant effect, inhibiting rapid fuel conversion. Therefore, the combustion process in the calciner takes place under difficult conditions [2]. The low partial pressure of oxygen and the low overall combustion temperature, caused by the high energy demand of the calcination reaction, result in a kinetic inhibition of the combustion reaction. To counteract this, the calciner should be designed for a retention time of at least 3s [3]. Designing for the required retention time is therefore decoupled from the requirements of the calcination process, so that it is now only dependent on the quality of the calciner fuel. Nowadays, the usual gas retention times of the calciner are 3-4s for lignite, hard coal, natural gas and oil and over $5 \mathrm{~s}$ for fuels that are difficult to ignite. The technological characteristics of fuel - taking solid fuels as an example - that influence good burn-out under the combustion conditions in the calciner are then essentially restricted to its reactivity (ignition and char burn-out) and its particle size. The reactivity can only be influenced by the drying and size reduction of the fuel, and is essentially dependent on the content of volatile components. The higher the content of volatiles, the better and faster the ignition of the fuel. The particle size depends on the extent to which the fuel can be costed and effectively ground. The finer the particle size distribution and the lower the amount of oversize material, the shorter the time required for complete burn-out. In contrast to these primary fuels, the number of possible secondary or alternative fuels is far larger, which significantly increases the range of difference in their combustion properties. In addition to calcining raw meal, the main criteria for the calciner design are complete burn-out of the calciner fuel without emission of organic, toxic residues, enough flexibility to enable the broadest possible range of fuels to be burnt, minimizing the of emissions such as NOx and CO, which make the calciner controlling easily [4]. 


\section{Nox Emissions Control by Extended Calciner Module}

Th modification on the exiting calciner with NOx calciner enables application of staged combustion with extension module (see figure 1). In the oxygen-deficient zone, part of the supplied fuel is converted substochiometrically. This generates unburnt gases that have the potential to reduce NOx. Depending on the reactivity of the fuel, NOx levels significantly lower than $500 \mathrm{mg} / \mathrm{Nm} 3$ of dry exhaust gas (referred to 10 per cent $\mathrm{O} 2$ ) are achieved. To meet more stringent NOx emission limits or to enable the use of poorlyreactive fuels, the calciner can be additionally equipped with an ammonia injection (SNCR) system. An additional primary measure to reduce NOx emissions with low volatile fuels is the newly-developed calciner. The pyroredox system, serves as a gasifying reactor which is connected upstream to the main calciner. The functional principle is shown in figure 2. As shown, the main calciner itself is disconnected from the kiln inlet chamber but as usual supplied with tertiary air. Therefore, the pyroredox reactor is separating the process in fuel gasification and NOx reduction in the pyroredox. The calcination and gasified fuel then burn out at low temperatures in the calciner. To enable this, up to 100 per cent of the fuel will be fed to the pyroredox from the penultimate cyclone. Shortly after the connection to the main calciner, only some remaining fuel, along with the major meal portion, is introduced via a second feeding point and serves for the calcination and the final burn-out of the denox gases. This promising concept is planned for new installations as well as for retrofits. The benefits are obvious as the system is suitable for many types of calciner fuels, no investment in secondary measures is required and savings can be made in terms of reagent consumption costs.

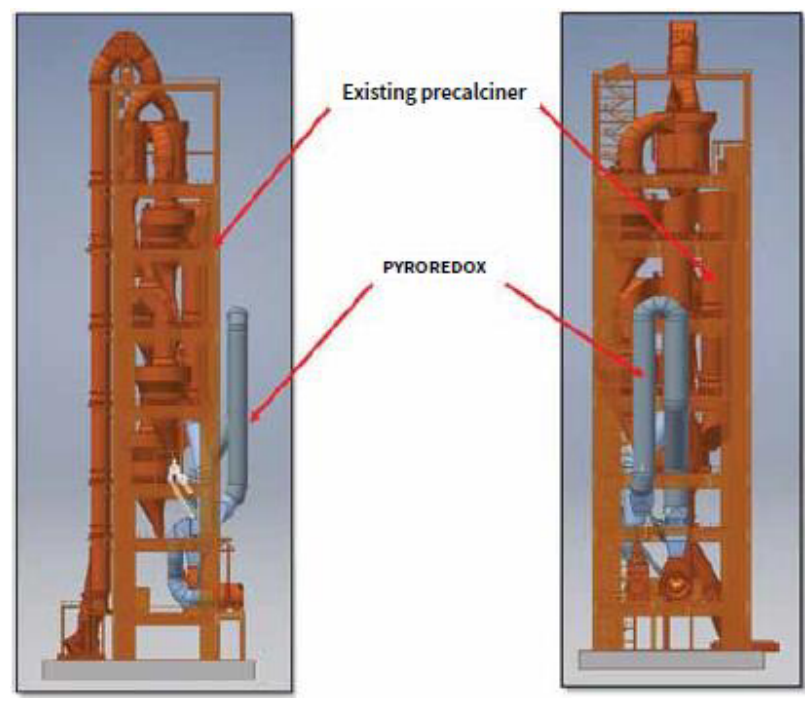

Figure 1. Extended gasifier calciner arrangement.

In the system design, the Nox produced in the kiln will be reduced by the gasifier calciner which extended outside of the preheater, The extended gasifier calciner will be divided into four zone. As in figure 2, In the first oxidizing zone, the combustion of the fuel, which is the coal mainly, will consume the oxygen totally. In the second gasification 
zone, which will fully utilize the Boudouard Reaction to reduce the $\mathrm{CO}_{2}$ to $\mathrm{CO}$ by the $\mathrm{C}$, In the third Redox zone, The Nox will be reduced to $\mathrm{N}_{2}$ by $\mathrm{CO}$ based on below main reaction mechanism.

$$
\begin{gathered}
2 \mathrm{NO}+\mathrm{CO} \rightarrow \mathrm{N}_{2}+\mathrm{CO}_{2} \\
2 \mathrm{NO}_{2}+4 \mathrm{CO} \rightarrow \mathrm{N}_{2}+4 \mathrm{CO}_{2}
\end{gathered}
$$

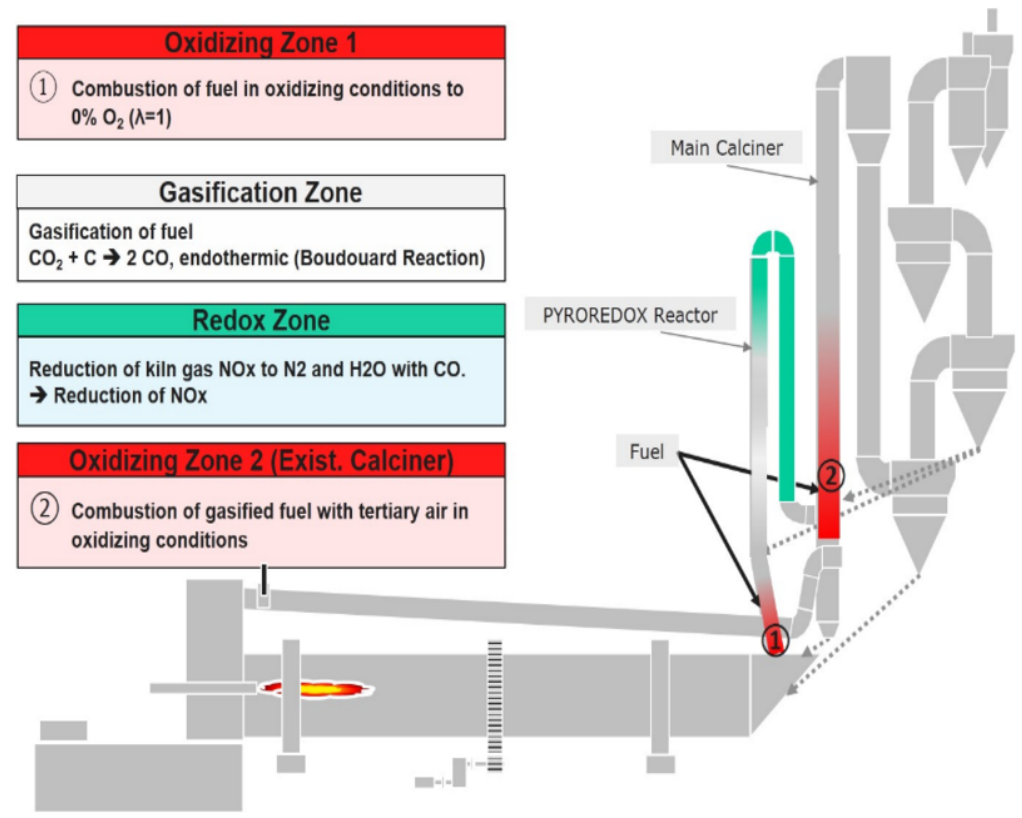

Figure 2. Extended gasifier calciner Nox reduction mechanism.

\section{Nox Emissions Control by SNCR System}

In the exiting calciner inlet, The Nox from the extended gasifier calciner will be totally reduced to $\mathrm{N}_{2}$, which means, all the Nox coming from the kiln is reduced in the exiting calciner inlet. The residue Nox which will be produce by the exiting calciner, Since the temperature in the exiting calciner is $850^{\circ} \mathrm{C}$ in averagely. So the Nox will be also produce in this temperature field. For the Nox produced in the exiting calciner. It should be fully utilizing the ammonia water (usually $23 \%$ in concentration) through SNCR system by the chemical reduction mechanism as below to reduce the Nox to $\mathrm{N}_{2}$ [5]. As in figure 3, The ideal gas temperature for the Nox reduction by ammonia water is $950 \cdot \mathrm{C}$ [6]. The ammonia water spraying gun will be arranged as figure 4. Mainly in the middle up the exiting calciner and $\mathrm{C} 5$ cyclone inlet.

$$
\begin{aligned}
& 4 \mathrm{NH} 3+4 \mathrm{NO}+\mathrm{O} 2 \rightarrow 4 \mathrm{~N}_{2}+\mathrm{H}_{2} \mathrm{O} \\
& 4 \mathrm{NH} 3+2 \mathrm{NO}_{2}+\mathrm{O} 2 \rightarrow 3 \mathrm{~N}_{2}+6 \mathrm{H}_{2} \mathrm{O}
\end{aligned}
$$




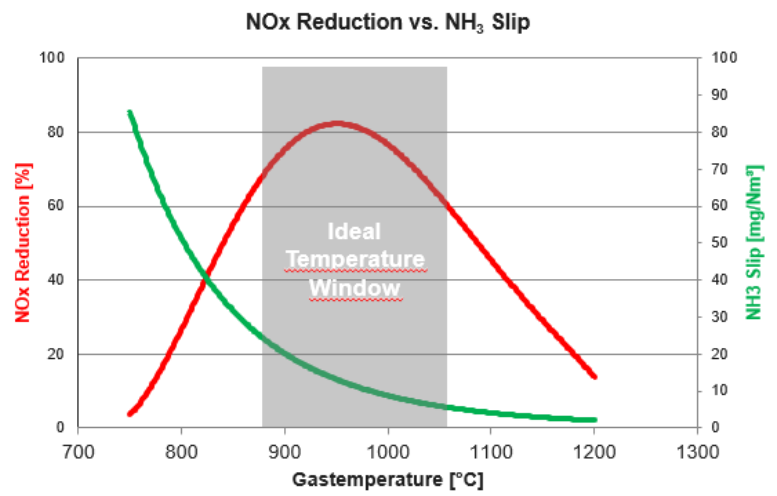

Figure 3. Best gas temperature reaction window.

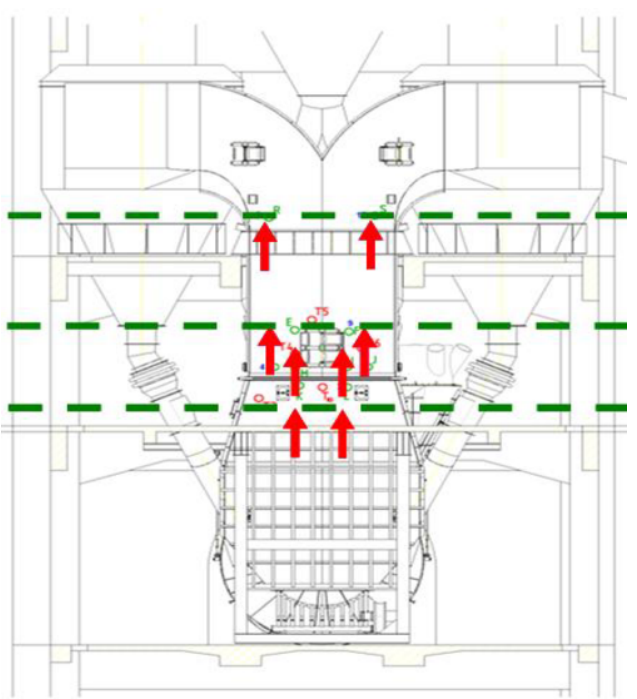

Figure 4. Ammonia water spraying gun arrangement in preheater system.

\section{Ammonia Water Consumption Calculation in SNCR System}

According to a cement plant which use the ammonia water (concentration $20 \%$, density $0.9070 \mathrm{~g} / \mathrm{mL}$ ) as the Nox reduction solvent in the SNCR system, the Nox emission target is below $50 \mathrm{mg} / \mathrm{Nm}^{3}$; the ammonia slippage in SNCR system is $5 \mathrm{mg} / \mathrm{Nm}^{3}$. The ammonia water Denox efficiency is $90 \%$ [7]. Clinker production is $6527 \mathrm{t} / \mathrm{d}$. With the extended gasifier calciner, the NOx is reduced to $0 \mathrm{ppm}$ in the exiting calciner inlet. The Nox in the $\mathrm{C} 1$ outlet is $230 \mathrm{mg} / \mathrm{m}^{3}$ ( $\mathrm{NO} 95 \%, \mathrm{NO}_{2} 5 \%$ ). The preheater gas volume in $\mathrm{C} 1$ outlet is $359032 \mathrm{Nm}^{3}$, Considering the ammonia water as the reduction solvent, The ammonia consumption calculation is as below.

NOx emission calculation (NOx concentration is $230 \mathrm{Mg} / \mathrm{Nm}^{3}$ )

$$
\mathrm{M}_{\mathrm{NOx}}=\mathrm{V}_{0} \times \mathrm{C}_{\mathrm{NOx}} \times\left(30.0057 \times \frac{0.95}{22.4}+46.0047 \times \frac{0.05}{22.4}\right)
$$


NOx emission in each hour is $486.33 \mathrm{Kg}$.

$$
\begin{gathered}
=359032 \times 230 \times\left(30.0057 \times \frac{0.95}{22.4}+46.0047 \frac{0.06}{22.4}\right) \\
=114.87 \times 10^{8}(\mathrm{mg} / \mathrm{h})
\end{gathered}
$$

And, 30.0057 - NO molecular weight; 46.0047 - $\mathrm{NO}_{2}$ molecular weight; 22.4 Molar Gas Volume;

And,

$$
\begin{gathered}
\text { NO Emission } \mathrm{M}_{\mathrm{NO}}=114.87 \times 95 \%=109.13(\mathrm{~kg} / \mathrm{h}) \\
\mathrm{NO}_{2} \text { Emission } \mathrm{M}_{\mathrm{NO} 2}=114.87 \times 5 \%=5.74(\mathrm{~kg} / \mathrm{h})
\end{gathered}
$$

NOx emission calculation

React with NO Ammonia consumption calculation

$$
\begin{aligned}
& 4 \mathrm{NH}_{3}+4 \mathrm{NO}+\mathrm{O}_{2}=4 \mathrm{~N}_{2}+6 \mathrm{H}_{2} \mathrm{O} \\
& 4 \times 17.031 \quad 4 \times 30.0057 \\
& \mathrm{~m}_{1} \quad 109.13 \mathrm{~kg} / \mathrm{h} \mathrm{X} \mathrm{90 \%} \\
& \mathrm{m}_{1}=55.92(\mathrm{~kg} / \mathrm{h})
\end{aligned}
$$

React with $\mathrm{NO}_{2}$ Ammonia consumption calculation

$$
\begin{aligned}
& 4 \mathrm{NH}_{3}+4 \mathrm{NO}+\mathrm{O}_{2}=4 \mathrm{~N}_{2}+6 \mathrm{H}_{2} \mathrm{O} \\
& 4 \times 17.031 \quad 4 \times 46.0047 \\
& \mathrm{~m}_{2} \quad 5.74 \mathrm{~kg} / \mathrm{h} \\
& \mathrm{m}_{2}=2.13(\mathrm{~kg} / \mathrm{h})
\end{aligned}
$$

Ammonia slippage calculation

$$
\mathrm{m}_{3}=592461 \times 5 \times 10^{-6}=2.96(\mathrm{~kg} / \mathrm{h})
$$

Ammonia consumption in theoretical calculation

$$
\mathrm{m}=\mathrm{m}_{1}+\mathrm{m}_{2}+\mathrm{m}_{3}=55.92+2.13+2.96=61.01(\mathrm{~kg} / \mathrm{h})
$$

Considering the actual operation, Beside the main reaction, Side reaction will occur accompanying the main reaction [8], Assuming the ammonia consumption lost in the side reaction is $5 \%$, The actual ammonia consumption is $5 \%$ [9], The actual ammonia consumption is $61.01 \mathrm{~kg} / \mathrm{h}$, Considering the ammonia water concentration is $20 \%$, The ammonia water consumption is $305 \mathrm{~kg} / \mathrm{h}$, The clinker production is $272 \mathrm{t} / \mathrm{h}$, The ammonia water consumption is $1.12 \mathrm{~kg} / \mathrm{t}$ clinker.

\section{Ammonia Water Consumption Optimization in Intelligent SNCR System}

After the Denox modification of the exiting calciner, it is found the ammonia water reduction efficiency is not low since the actual ammonia consumption is $3.5 \mathrm{~kg} / \mathrm{t}$ clinker, The ammonia water reduction efficiency is $32 \%$. The ammonia controlling spraying controlling strategy is applied to reduce the ammonia water consumption and raise the reduction efficiency [10].

By the advanced process control, the Pyro system operation parameter can be studied and forecasted by the controlling system. In figure 5, the current process state is described. In figure 6, the estimation model is established and the process state is forecasted [11]. 


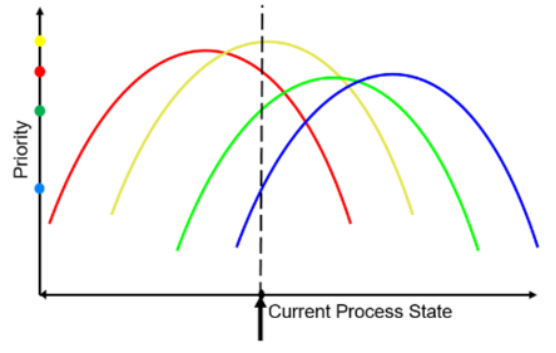

Figure 5. The current process state.

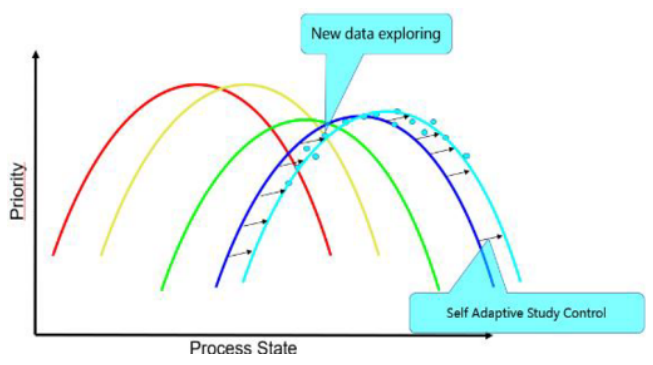

Figure 6. The forecasted process states.

\section{Conclusion}

With the modification in the exiting calciner, the Nox emission coming from the kiln can be totally reduced. For the Nox produced in the calciner, the intelligent SNCR system can reduce the Nox emission to be less than $50 \mathrm{mg} / \mathrm{Nm}^{3}$ by spraying the ammonia water. With the intelligent SNCR to forecast the process state, the ammonia consumption can be substantially reduced and the ammonia water reduction efficiency can be raised to $70 \%$. In the combination of the calciner modification with the intelligent SNCR system to control the ammonia water spraying is demonstrated to be the most efficient DeNox solution in pyro system of the cement plant.

\section{References}

[1] Lyon P K H and James E 1986 Discovery and development of the thermal DeNox process Ind. Eng. Chem. Fundam. 25 (1) 19-24.

[2] Salimian S 1980 Kinetic study of no removal from combustion gases by injection of NHi-Constraining compounds Combustion Science and Technology 23 225-230.

[3] Leckner B, Maria K, Dam-Johansen K, et al. 1991 Influence of additives on selective noncatalytic reduction of nitric oxide with ammonia in circulating fluidized bed boilers Industrial \& Engineering Chemistry Research 30 (11) 2396-2404.

[4] Duo W, Johansen K D and Ostergaard K 1992 Kinetics of the gas-phase reaction between nitric oxide, ammonia and oxygen Canadian Journal of Chemical Engineering 70 1014-1020.

[5] Takahashi S, Yamashita I and Korematsu K 1990 Influence of initial concentration on DeNOx process by ammonia addition JSME International Journal, Series II: Fluids Engineering, Heat Transfer, Power, Combustion, Thermophysical Properties 33 (2) 377-383.

[6] Kasuya F G, Johnsson J E and Dam Johansen K 1995 The thermal DeNOx process: Influence of partial pressure and temperature Science $\mathbf{5 0} 1455-1466$.

[7] Ostberg M and Dam-Johansen K 1994 Empirical modelling of the selective non-catalytic reduction of NO: comparison with large scale experiments and detailed kinetic modelling Chemical Engineering Science 49 (12) 1897-1904.

[8] Jeral A and Caton Z X 2004 The selective non-catalytic removal (SNCR) of nitric oxides from engine exhaust streams: Comparison of three processes Transactions of the ASME 126234.

[9] Caton J A, Narney J K, Cariappa C, et al. 1995 The selective non-catalytic reduction of nitric oxide using ammonia at up to 15\% oxygen Canadian Journal of Chemical Engineering 73 (3) 345-350.

[10] Anony 2002 Coal plant achieves 99\% NOx and Sox removal with multi-pollutant technology Power Engineering 512.

[11] Bradley H J and Jones B M 2002 Reducing global NOx emissions: Promoting the development of advanced energy and transportation technologies Ambio. 31 (2) 141-149. 